\title{
Cost-effectiveness of replacing skeletal traction by interlocked intramedullary nailing for femoral shaft fractures in a provincial trauma hospital in Cambodia
}

\author{
Richard A. Gosselin • Merja Heitto • Lew Zirkle
}

Received: 31 December 2008 /Revised: 23 April 2009 /Accepted: 23 April 2009/Published online: 13 May 2009

(C) The Author(s) 2009. This article is published with open access at Springerlink.com

\begin{abstract}
In this article the costs and effectiveness of introducing the SIGN nailing system for femoral shaft fractures in a provincial trauma hospital in Cambodia are compared to those of Perkin's traction treatment. At an average cost per patient of $\$ 1,107$ in the traction group and $\$ 888$ in the nail group $(p<0.01)$, and with better clinical outcomes in the nail group, internal fixation is more costeffective than conservative treatment.
\end{abstract}

\section{Introduction}

Economic development in low-income countries is accompanied by an increase in the burden of trauma, particularly injuries due to road traffic accidents [8]. It also provides the opportunity to improve on the management of some of those injuries, such as fractures of the femur. Skeletal traction or closed manipulation and casting remain the most common treatments of long bone fractures in resource-poor settings. The literature from developed countries is replete with studies showing better functional outcomes with locked intramedullary nails for femoral $[10,16]$ and tibial $[2,4,15]$ fractures over conservative management, even in the adolescent population [12]. In poor countries, lack of

R. A. Gosselin $(\bowtie)$

School of Public Health, University of California at Berkeley,

Berkeley, CA, USA

e-mail: froggydoc@comcast.net

\section{Heitto}

Emergency Hospital,

Battambang, Cambodia

L. Zirkle

Surgical Implant Generation Network (SIGN),

Richland, WA, USA human and material resources, and an often unsafe surgical environment, may preclude internal fixation of long bones [11]. Femoral shaft fractures are thus treated with skeletal traction with its known complications of prolonged bed rest and hospitalisation, along with pin tract infections, decubitus ulceration, malunion/nonunion and shortening [5].

The Kingdom of Cambodia, in south-east Asia, has a population of around 14 million people, with a per capita nominal GDP of $\$ 606$, which is slowly but steadily increasing. Battambang, the capital of the northwest province of the same name, is the second largest city in the country with a population slightly over a million. All major injuries from the province are treated at the Emergency Surgical Centre, a hospital almost exclusively devoted to trauma [6]. Emergency is an Italian nongovernmental organisation (NGO) that provides surgical care to all, free of charge. Until recently, all adolescent and adult femoral shaft fractures were treated with Perkin's skeletal traction, allowing early knee mobilisation but requiring a minimum of six weeks in bed [5]. In early 2007, the Surgical Implant Generation Network (SIGN) nailing system was introduced. It is a solid nail, designed to be inserted without image intensification, fracture table or powered reaming, thus specifically adapted to resourcepoor environments. An external jig allows proximal and distal interlocking. The nail has a typical tibial nail configuration, but is also used for femurs and humeri, simplifying significantly the necessary inventory.

The purpose of this paper was to try to compare the costs and the change in outcomes (if any) from this transition. Economic evaluations, such as a cost-effectiveness analysis (CEA), are widely used tools in developed countries to compare different interventions or strategies $[1,3,7,13]$. Although the World Health Organisation (WHO) has published standard guidelines for CEAs, there is a dearth 
of such studies in low income countries [14]. The purpose of a CEA is to assess the relative value of one intervention over another, for a given problem or condition. One intervention is more cost-effective if: (1) it is less costly with an equal or better outcome, (2) it is less costly with a worse outcome, but the added benefit of the alternative is not worth the extra cost, or (3) it is more costly with better outcomes, and the added benefit is worth the added cost [13]. When is added benefit worth the added costs? The answer depends on availability of human and material resources, and also moral, economical, legal and societal values.

\section{Materials and methods}

Only isolated fractures of the femoral shaft not involving either metaphyses were included. At the time of data collection, the first 49 consecutive SIGN nails had a followup of at least 16 weeks. The last 50 consecutive patients with femoral shaft fractures treated in skeletal traction formed the comparison group, so as to minimise the effect of time on costs. The hospital records, X-ray files and outpatient records were reviewed for all patients and data collected for age, sex, type of fracture, time of fracture, time in traction, length of hospital stay (LOS), weight bearing status at discharge and fracture healing at last follow-up. Of the 49 nails, 38 were inserted for fresh fractures (i.e. less than six weeks), including one tibial nailing which was excluded, and 11 for nonunion, including three tibial nails. These nonunions were excluded from the analysis, leaving 87 patients aged 14 years or more, with 89 femoral shaft fractures, covering a seven-month period.

A nonunion was diagnosed in the traction group if at last follow-up (minimum four months, mean 6.5 months) the fracture was still mobile clinically and there was little or no progress in radiological consolidation. In the nail group it was diagnosed if at last follow-up (minimum four months, mean 5.5 months) there was little or no progression of callus on X-rays, or evidence of hardware failure. A malunion was diagnosed if a fracture had healed with a 20 -degree or more angulation in any plane, a 20-degree malrotation or shortening of more than 2.5 $\mathrm{cm}$. Other recorded complications included superficial (above fascia) or deep (below fascia) infections, and nerve damage.

Fixed costs such as infrastructure costs and depreciated costs for initial equipment were the same for both groups. Variable costs were different; they included hospital per diem, operating room time, equipment, use of blood products, physiotherapy, X-rays, and supplies such as dressings, drugs and/or orthotics. The vast majority of patients were farmers, often sustenance farmers with no fixed income, so it was not possible to factor in societal costs, such as lost wages. All costs are from the payer/ provider perspective. Unfortunately, because of the retrospective nature of the study, no data were collected about time to return to normal daily activities.

Statistical analysis was done using the Stata I/C 9.0 software package, with significance at $p<0.05$.

\section{Results}

There were no hospital deaths in either group. Mean age, mean time since injury, proportion of open versus closed, and simple versus comminuted fractures were not statistically different between groups. In the Perkins traction group, 50 patients with 52 femoral fractures had a mean length of stay (LOS) of 52.3 days, with a mean time in traction of 45.6 days. Of the 37 patients in the nail group, there were eight who were already in Perkins traction when the SIGN program was started, and before the backlog was cleared, some new patients were put in temporary traction for a longer period than those toward the end of the series. The average LOS for this group was 34.9 days, with an average time in traction of 20.7 days and an average LOS after nailing of 14.2 days. These results are summarised in Table 1. At the time of discharge, eight of 50 patients $(16 \%)$ in the traction group and 21 of 37 patients $(57 \%)$ in the nail group were fully weight bearing $(p<0.001)$, as shown in Table 2 . The mean length of nailing surgery was 2.5 hours, which reflects the repeated learning curve of rotating surgeons. A total of 29 of 37 nails were inserted in an antegrade fashion, and all but one were statically interlocked using all four screw holes, another reason for prolonged surgery time. Of interest is that, even if they are excluded from the study, the 11 nailings for nonunion, six of which were Emergency patients that had failed Perkins treatment, averaged 3.8

Table 1 Data summary for traction and nails groups

\begin{tabular}{lll}
\hline Variable & Traction & Nails \\
\hline Patients & 50 & 37 \\
Fractures & 52 & 37 \\
Mean age (years) & $33.6(14-72)$ & $32.1(14-68)$ \\
Femurs & 52 & 37 \\
Closed/open & $36 / 16$ & $30 / 7$ \\
Simple/Comminuted & $16 / 36$ & $16 / 21$ \\
Mean time since injury (days) & $3.1(0-35)$ & $3.7(1-42)$ \\
Mean length of stay (LOS) (days) & 52.3 & 34.9 \\
Mean time in traction (days) & 45.6 & 20.7 \\
Mean length of surgery (hours) & - & 2.5 \\
\hline
\end{tabular}


Table 2 Weight-bearing status at time of discharge

\begin{tabular}{lll}
\hline WB status & Traction (total 52) & Nails (total 38) \\
\hline Full WB & $8(16 \%)$ & $21(57 \%)$ \\
Partial WB & $41(78 \%)$ & $16(41 \%)$ \\
Non WB & $3(6 \%)$ & $1(2 \%)$ \\
\hline
\end{tabular}

$W B$ weight bearing

hours in operative time. For the fresh fractures, the pre and post-op $\mathrm{Hb}$ averaged 11.1 and 8 gms, respectively, and 22 patients in the nail group received an average of 2.5 whole blood units.

Medical records and complete X-ray files were available for 46 patients in the Perkins group and 36 patients in the SIGN group. The 46 traction patients had 46 fractures, 34 of them (74\%) showing clinical and radiological signs of consolidation, ten $(22 \%)$ signs of delayed or nonunion and two (4\%) malunions. A total of 33 of the $36(92 \%)$ of the nailed femurs showed radiological evidence of advanced or complete healing and only three $(8 \%)$ did not show significant amounts of callus on X-rays $(p<0.001)$. All three had static interlocking with some amount of distraction. Outcomes are summarised in Table 3.

The total costs in \$US are summarised in Table 4. Costs incurred in Euros or in the local currency, the Riel, were converted to \$US at the prevailing rate for the sample period. There were an average of six X-rays taken for the nail group and ten for the traction group. Most patients in the nail group received two hours of physiotherapy every day, whereas the Perkins group received one hour a day, doing most of the exercises on their own. The per diem was calculated by dividing the average monthly operating costs $(\$ 50,803)$ by the number of beds/days $(106 \times 31)=\$ 15.50 /$ day, which includes nursing care, food, laundry and hospital cleaning. Twenty-two patients in the traction group needed a cast-brace before discharge at a unit cost of $\$ 120$; there were none in the nail group. The sum cost for the 50 patients treated in traction was $\$ 47,060$, or $\$ 941$ per patient. The costs for per diem alone in this group account for $88 \%$ of the total costs. The sum cost for the 37 patients treated with a SIGN nail was $\$ 30,347$, or $\$ 820$ per patient. The per diem costs for this group represent $66 \%$

Table 3 Outcomes at minimum 16 weeks follow-up

\begin{tabular}{lll}
\hline Outcome & Traction & Nails \\
\hline Follow-up $>16$ weeks & 46 & 36 \\
Fractures healed & $34(74 \%)$ & $33(92 \%)$ \\
Malunion & $2(4 \%)$ & 0 \\
Nonunion & $10(22 \%)$ & $3(8 \%)$ \\
\hline
\end{tabular}

Table 4 Comparative total costs of inputs for both groups, \$US

\begin{tabular}{lll}
\hline Cost category & Traction & Sign nail \\
\hline Pins & 156 & 24 \\
Temporary traction & 0 & 60 \\
Perkin's frame & 250 & 40 \\
Crutches & 750 & 555 \\
X-rays & 442 & 189 \\
Physiotherapy & 2150 & 1113 \\
Length of stay (per diem) & & \\
$\quad$ Pre-op & & 11872 \\
$\quad$ Post-op & & 8143 \\
$\quad$ Total & 40532 & 20015 \\
Cast-brace & 2640 & 0 \\
Implant & 0 & 5550 \\
Operating room time & 0 & 2082 \\
Transfusion & 0 & 460 \\
Miscellaneous (drugs, lab) & 140 & 259 \\
Total & 47,060 & 30,347 \\
Total per patient & 941 & 820 \\
\hline
\end{tabular}

of total costs $(p<0.01)$. The per patient difference in costs is thus $\$ 121$.

There was one deep peroneal nerve palsy, which resolved completely in the hospital without further treatment. There were 14 pin tract infections in the Perkins group, two of which required surgical debridement, adding less than $\$ 50$ to the total costs. There was one superficial infection in the nail group, which responded well to surgical debridement, and one deep infection which required nail removal and delayed re-nailing. This added less than $\$ 250$ to the overall costs, bringing the per patient costs up to $\$ 826$. If we also include the surgical treatment of nonunions, and assume that all three in the SIGN group and all ten in the traction group will be nailed or re-nailed, the overall costs in the SIGN group increases to $\$ 32,828$ or $\$ 888$ per patient, and the overall costs in the traction group increase to $\$ 55,330$ or $\$ 1,107$ per patient. In this scenario, the per patient difference increases to $\$ 219$.

\section{Discussion}

The SIGN nailing system has a long track record of success throughout the world. Others have reported on its success in resource-poor settings [9]. As with any new technology, there is a learning curve, no matter how user-friendly the SIGN system is. As surgeons and operating theatre nurses become more proficient with its use, operative time should decrease substantially, and be more in line with the 60-90 minutes reported elsewhere. At the time of data collection, patients were kept in bed and received antibiotics for a 
week after surgery, and discharged only after suture removal at 14 days. Now patients are mobilised the first day after surgery, receive antibiotics for 48 hours, and are most often discharged within a week. Throughout the world, there are dozens of sites that have considerable experience with the SIGN system and they report an average LOS of five days. If this were true at this site, the costs per patient would actually drop to around $\$ 350$ (ideal scenario). Obviously, costs are very context-specific, and a $\$ 15.50$ per diem might not be reproducible in many settings. With a difference of $\$ 219$ per patient in the complication scenario, it would require treatment of five patients surgically to make up for the costs of treating the sixth one. The difference with the ideal scenario would be around $\$ 757$ per patient. In other words, the cost of treating one patient in traction would be approximately the same as treating three patients with a nail.

There are many flaws to such a study. It is neither randomised nor prospective. The control group is retrospective and not matched. Even though they followed one another, the two groups are not synchronous. The 16-week minimum follow-up is short and many would argue that nonunion cannot be discussed before six months, so the $22 \%$ and $8 \%$ nonunion rates in the traction and nail groups, respectively, may be falsely high, but it still seems reasonable to assume that the outcomes are better with internal fixation, as suggested by most of the literature. The fact that $57 \%$ of patients treated with nails and only $16 \%$ of those treated in traction were full weight-bearing upon discharge also supports this. Although unsubstantiated, it is probably not unreasonable to think these patients will return sooner to gainful employment.

It took no more than 30 nails for the costs per patient to equal those treated in traction. As the surgical centre moves closer to the ideal scenario, costs will continue to fall. It seems safe to conclude that, in this particular setting, better outcomes at lower expenditure make SIGN nailing of adult femoral shaft fractures much more cost-effective than Perkins skeletal traction.

Open Access This article is distributed under the terms of the Creative Commons Attribution Noncommercial License which permits any noncommercial use, distribution, and reproduction in any medium, provided the original author(s) and source are credited.

\section{References}

1. Bozic KJ, Rosenberg AG, Huckman RS, Herndon JH (2003) Economic evaluation in orthopaedics. J Bone Jt Surg (Am) $85: 129-142$

2. Busse JW, Bhandari M, Sprague S et al (2005) An economic analysis of management strategies for closed and open grade 1 tibial shaft fractures. Acta Orthopaedica 76(5):705-712

3. Clinkscales CM, Peterson HA (1997) Isolated closed diaphyseal fractures of the femur in children: comparison of effectiveness and cost of several treatment methods. Orthopedics 20(12): $1131-1136$

4. Downing ND, Griffin DR, Davis TR (1997) A comparison of the relative costs of cast treatment and intramedullary nailing for tibial diaphyseal fractures in the UK. Injury 28:373-375

5. Gosselin RA, Lavaly DJ (2007) Perkins traction for adult femoral shaft fractures: a report on 53 patients in Sierra Leone. Int Orthop Vol 31(5):697-702

6. Gosselin RA, Heitto M (2008) Cost-effectiveness of a district trauma hospital in Battambang, Cambodia. World J Surg 32 (11):2450-2453

7. Haetjens P, Annemans L (2003) Health economics and the orthopedic surgeon. J Bone Joint Surg (Br) 85:1093-1099

8. Hofman K, Primack A, Keusch G, Hrynkow S (2005) Addressing the growing burden of trauma and injury in low and middle income countries. Am J Public Health 95(1):13-17

9. Ikem IC, Ogunlusi JD, Ine HR (2007) Achieving interlocking nails without use of an image intensifier. Int Orthop 31(4):487490

10. Johnson KD, Johnston DW, Parker B (1984) Comminuted femoral shaft fractures: treatment by roller traction, cerclage wires and an intramedullary nail, or an interlocking intramedullary nail. J Bone Joint Surg (Am) 66(8):1222-1235

11. Levine AC, Presser DZ, Rosborough S et al (2007) Understanding barriers to emergency care in low-income countries: view from the frontline. Prehosp Disaster Med 22(5):467-470

12. Reeves RB, Ballard RI, Hughes JL (1990) Internal fixation versus traction and casting of adolescent femoral shaft fractures. J Pediatr Orthop 10(5):592-595

13. Subak LL, Caughey AB (2000) Measuring cost-effectiveness of surgical procedures. Clin Obs Gynaec 43(3):551-560

14. Tan Torres-Edejer T, Baltussen R, Adam T, Hutubessy R et al (2003) WHO guidelines to cost-effectiveness analysis. World Health Organization, Geneva

15. Toivanen JA, Hirvonen M, Auvinen O et al (2000) Cast treatment and intramedullary locking nail for simple and spiral wedge tibial shaft fractures: a cost-benefit analysis. Ann Chir Gynaecol 89 (2):138-142

16. Webb LX, Gristina AG, Fowler HL (1988) Unstable femoral shaft fractures: a comparison of interlocking nailing versus traction and casting methods. J Orthop Trauma 2(1):10-12 